This item was submitted to Loughborough's Research Repository by the author.

Items in Figshare are protected by copyright, with all rights reserved, unless otherwise indicated.

\title{
The development of novel interchangeable pistons for pressure performance optimization in a gas-operated dead weight pressure balance
}

PLEASE CITE THE PUBLISHED VERSION

http://dx.doi.org/10.1088/0026-1394/46/3/020

PUBLISHER

(C) BIPM and IOP Publishing Ltd

VERSION

AM (Accepted Manuscript)

LICENCE

CC BY-NC-ND 4.0

\section{REPOSITORY RECORD}

Mohamed, Wan A.M.W., and Jon N. Petzing. 2019. "The Development of Novel Interchangeable Pistons for Pressure Performance Optimization in a Gas-operated Dead Weight Pressure Balance”. figshare. https://hdl.handle.net/2134/9244. 
This item was submitted to Loughborough's Institutional Repository (https://dspace.lboro.ac.uk/) by the author and is made available under the following Creative Commons Licence conditions.

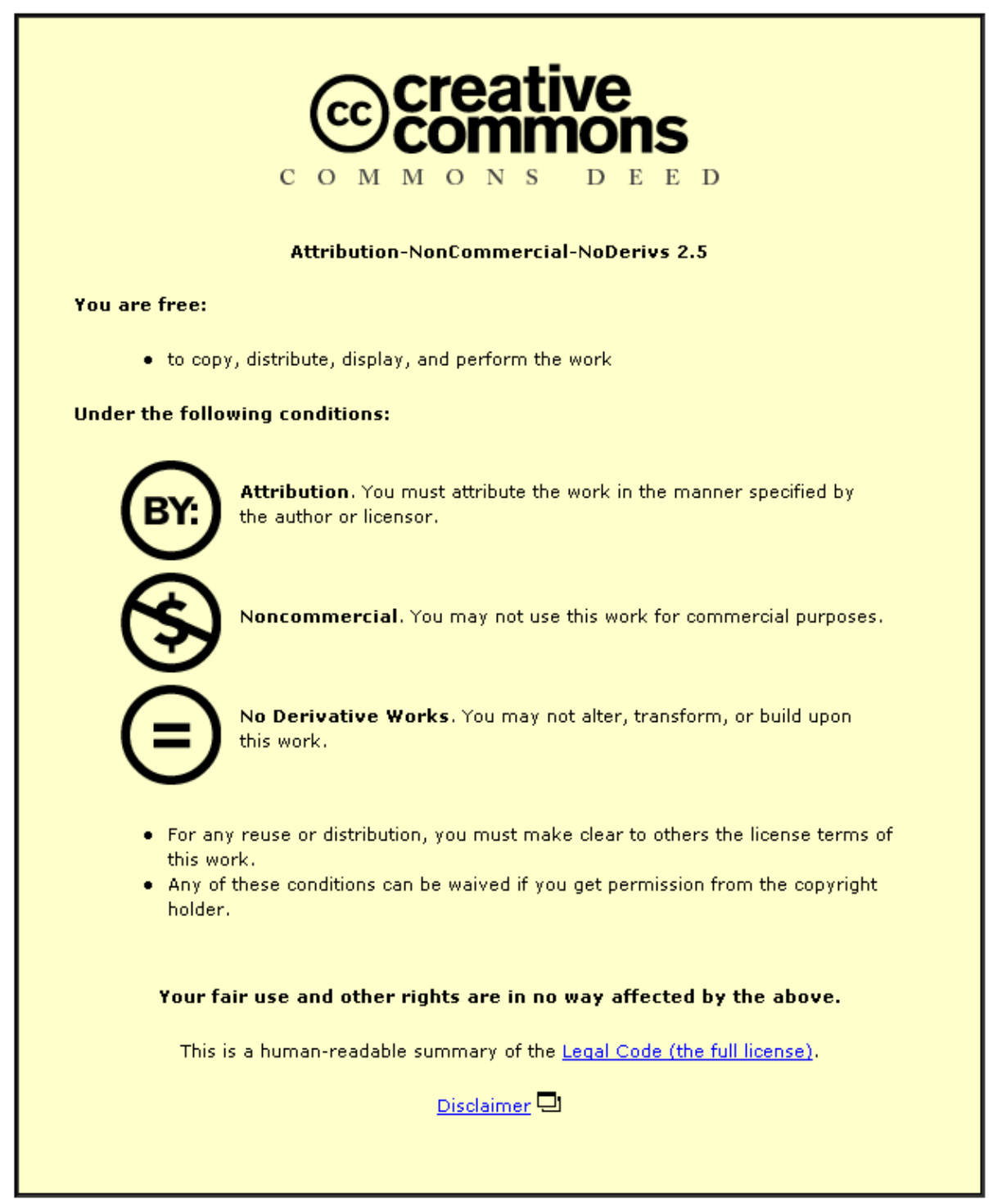

For the full text of this licence, please go to: http://creativecommons.org/licenses/by-nc-nd/2.5/ 
The Development of Novel Interchangeable Pistons for Pressure Performance Optimisation in a Gas-Operated Dead Weight Pressure Balance

${ }^{1}$ Wolfson School of Mechanical \& Manufacturing Engineering, Loughborough University, Loughborough, Leicestershire, LE11 3TU, UK

${ }^{2}$ National Metrology Laboratory, SIRIM Berhad, 43900 Sepang, Malaysia

Contact Details: Jon Petzing 


\section{ABSTRACT}

The texture of surfaces within a Piston Cylinder Assembly (PCA) can influence the

24 pressure performance of gas-operated Dead Weight Pressure Balances (DWPB). In order 25 to systematically study this response, it has been necessary to design, develop and 26 manufacture uniquely interchangeable $35 \mathrm{~mm}$ diameter PCAs for use in a novel hybrid gasoperated DWPB with high mechanical, thermal and pressure stability. This work reports the development of the PCAs and the validation of the DWPB design, allowing the performance characteristics of the interchangeable PCAs to be understood, in terms of

30 variations of effective area calculations. This is achieved by investigating the pressure 31 responses of the DWPBs by changing the speed and direction of rotation. The results 32 demonstrate the stability of the gas-operated DWPB design when used in gauge mode, and importantly allow the verification of the performance of the interchangeable PCAs. 


\subsection{INTRODUCTION}

Dead Weight Pressure Balances (DWPBs) are widely used around the world to generate pressures with high levels of accuracy, from several $\mathrm{kPa}$ to several hundred $\mathrm{MPa}$ [1-3]. Both, hydraulic and gas operated DWPBs provide one of two primary methods for deriving pressure from the base units of mass, length and time; the other being the liquid manometer [1-3]. One of the major differences between these two (the DWPB and the manometer) types of instrument is their measuring range, where the former can measure in a very wide range, whilst the latter is usually limited to near atmospheric pressure regions.

The DWPB's principle component consists of a Piston-Cylinder Assembly (PCA) with a known effective area $\left(A_{0}\right)$, which is oriented vertically to the earth's gravitational force. A PCA consists of a finely lapped and polished piston, fitting into a geometrically and dimensionally matching cylinder of similar surface characteristics.

Weights of known mass can be loaded onto the piston, so that the upward vertical force (due to the pressure) acting on the piston (across the $A_{0}$ ) exactly balances the total downward gravitational force, so that at equilibrium the piston floats while falling at its natural fall rate. The piston and weights are rotated during operation in order to alleviate frictional components and to ensure concentricity, thus helping the piston to float freely [2,3]. It should be noted that in some DWPB designs, the cylinder may be rotating instead of the piston [4], but the physical principle remains the same.

The pressure is defined as the ratio of the total downward gravitational force to the $A_{0}$, where $A_{0}$ is most commonly determined through a comparison against another DWPB or a 
mercury manometer, although dimensional characterizations have also been used [5-9].

60 The fact that the force can be measured with greater accuracy than area is well known. To

61 increase the accuracy of pressure measurement it is necessary to better understand the determination of $A_{0}$, and hence the correct determination of the $A_{0}$ becomes the core issue related to further development of the DWPB as a primary standard.

Pressure (in gauge mode) is related to the effective area [1-3], via Equation 1,

$$
p=\frac{\sum_{i} m_{i}\left(1-\rho_{a} / \rho_{m}\right) g_{L}+\pi D T}{A_{0}(1+\lambda p)\left[1+\left(\alpha_{p}+\alpha_{c}\right)\left(t-t_{r e f}\right)\right.} \pm\left(\rho_{f}-\rho_{a}\right) g_{L} h
$$

where $p$ is the calculated pressure at a reference level $h$ from the base of the piston; $m_{i}$ is the mass of the ith weight; $\rho_{a}$ is the air density; $\rho_{m}$ is the density of the weight; $g_{L}$ is the local acceleration of gravity; $D$ is the diameter of the piston; $T$ is the surface tension of the pressure transmitting fluid used; $A_{0}$ is the effective area of the PCA at atmospheric pressure and reference temperature, $t_{r e f}$; $\lambda$ is the pressure distortion coefficient of the PCA; $\alpha_{p}$ and $\alpha_{c}$ are the linear thermal expansion coefficients of the piston and cylinder respectively, $t$ is the temperature of the PCA at the time pressure being measured; $t_{\text {ref }}$ is the reference temperature of the PCA; $\rho_{f}$ is the density of the pressure transmitting fluid; and $h$ is the distance between the piston base and a selected reference level. 
The current method for determining the effective area of a PCA relies on the neutral

80 surface between the cylinder and piston walls, with $A_{0}$ currently being defined as [2, 5]:

$$
A_{0}=\pi r_{0}^{2}\left[1+\frac{h_{0}}{r_{0}}-\frac{1}{r_{0}\left(p_{1}-p_{2}\right)} \int_{0}^{l}[(u+U) d p / d x] d x\right]
$$

where $r_{0}$ is the radius of the piston at the lowest extent of the engagement length between piston and cylinder; $h_{0}$ is the radial separation between two surfaces of the piston and cylinder at the same level as $r_{0}$; $p_{I}$ is the pressure being applied at the lowest extent of the engagement length, $p_{2}$ is the pressure around the top end of the piston (atmospheric pressure in gauge mode operation, or reference vacuum for absolute mode operation); $u$ and $U$ are the radial deviations from the radii of the piston and cylinder respectively at the lowest extent of the engagement length. For a PCA with a perfect geometry $(u=U=0$, i.e. constant radial clearance) the effective area, $A_{0}$ is exactly the arithmetic mean of the area of piston and cylinder [3].

Theoretical understanding and manufacturing improvements have allowed the gas-operated DWPB to develop over the last forty years, resulting in pressure determination from a few $\mathrm{kPa}$ to several hundred MPa. However in practice, besides the effects of gas leakage through the PCA clearance, other possible sources of uncertainty have been recognised, such as inconsistencies in PCA geometric form, inclination of the PCA, eccentricities of applied load etc [6], although not necessarily quantified. One aspect which has not been reported is the affect that piston (and/or cylinder) surface texture or structure, has on the fluid flow characteristics and hence the effective area determination. This is an element that is not modelled or taken into account within Eqs 1 and 2. 
Investigating surface texture characteristics of PCAs on DWPB performance is challenging, with the following key issues identified in order to enable this research:

- Interchangeable PCAs are required to explore a range of surface textures (random and structured), with different pistons being used in common cylinders.

- Methods of pre-determined texturing of PCA surfaces (typically Tungsten Carbide) require investigation and implementation.

- DWPB units are required which allow integration and interchangeability of PCA units, with high thermal stability.

- Any new design of PCA (and DWPB) requires metrological assessment with respect to primary standards, before it can be used to investigate the impact of process variables, to ascertain the mechanical, thermal and pressure stability.

This paper describes the design, development and manufacture of uniquely interchangeable $35 \mathrm{~mm}$ PCAs, along with the design and manufacture of a novel hybrid gas-operated analysis of low rotational spin speed and spin direction pressure related characteristics have been completed, along with direct calibration to UK national standards. 


\subsection{DESCRIPTION OF INSTRUMENTS}

The development of the DWPB detailed in this work, has been necessary to allow straight forward PCA interchangeability, resulting in a unique design $[10,11]$ that recognises elements of other pressure balances $[2,12,13]$. The DWPB design has been optimised to specifically enable research to be completed on understanding dimensional tolerance and surface characteristic issues of the $35 \mathrm{~mm}$ PCAs. However, this has necessitated the understanding of various potential error sources, and specifically in this case, issues of spin direction and spin speed and the effect on the generated pressures at low rotational speeds.

\subsection{Piston cylinder assembly (PCA)}

Pistons and cylinders were manufactured from Dymet Grade DF6 Tungsten Carbide (Table 1). Pistons were constructed from hollow Tungsten Carbide blanks $(60 \mathrm{~mm}$ height, $25 \mathrm{~mm}$ inner diameter, $35 \mathrm{~mm}$ outer diameter) bonded with a 316 Stainless Steel head $(30 \mathrm{~mm}$ height, $25 \mathrm{~mm}$ outer diameter) with a hemispherical cup on the top surface to accommodate the interfacing 316 Stainless Steel ball-bearing. Cylinders were manufactured from hollow Dymet Grade DF6 Tungsten Carbide blanks (40mm in height, 35mm inner diameter, 52 $\mathrm{mm}$ in outer diameter). The pistons and cylinders are illustrated in the DWPB assembly drawing in Figure 1.

The majority of commercially available PCA combinations can be described as matched pairs, with gap clearances typically in the order of $0.5 \mu \mathrm{m}$ to $1 \mu \mathrm{m}$ for gas based DWPBs. This research programme has required the development of a large number of pistons, which uniquely have operational interchangeability with a number cylinders, with gap clearances of approximately $1 \mu \mathrm{m}$. Eight interchangeable pistons (labelled as $\mathrm{P}_{1}$ to $\mathrm{P}_{8}$ 
respectively) and four interchangeable cylinders (labelled as $\mathrm{C}_{1}$ to $\mathrm{C}_{4}$ respectively) have been produced using rotary lapping and polishing techniques.

\subsection{The Dead Weight Pressure Balance (DWPB)}

Two identical gas-operated DWPBs were designed and manufactured for measuring pressures with an uncertainty budget of approximately 10ppm $(k=2)$, as detailed in Figure

1. The base of each DWPB was triangular in shape (25mm thick HE15 aluminium alloy), supported with 3 adjustable leveling feet. The 316 Stainless Steel mounting post was 90 $\mathrm{mm}$ in diameter and $214 \mathrm{~mm}$ in height. A large overhang type weight loading bell (102 $\mathrm{mm}$ inner diameter) with associated ring weights was designed in order to accept very large PCAs (35 $\mathrm{mm}$ and $50 \mathrm{~mm}$ diameter). The maximum pressure specification for the

The PCA cylinder was seated vertically on top of an o-ring, located in a groove inside the mounting post, secured using a 316 Stainless Steel cylinder retainer for pressure sealing purposes, consequently forming a free-deformation type of assembly. The PCA piston was secured by a 316 Stainless Steel piston retainer, acting as a retainer when the pressure increased beyond the equilibrium point. A piston-retainer coupled with a 316 Stainless Steel upper-bearing washer acted as a supporting mechanism when pressure decreased below the lower equilibrium point. This mechanism enabled the piston and associated weights to rotate on the thrust bearing while the piston was fully seated.

A ball bearing was used as a non-rigid point load interface mechanism between the piston and the overhang-type weight loading bell. 316 Stainless Steel ring weights were stacked at the lower end of the loading bell (lower centre of gravity relative to the PCA), hence 
175 improving the stability of the rotating piston (note that all weights, loading bells, pistons and other load elements were UCAS traceably calibrated). Consequently loaded weights were free to pivot, while maintaining the center of gravity coincident with the piston's axis. This design eliminated non-vertical (side loading) forces which may occur due to slight misalignment of loaded components [13].

The window-type weight loading bell was designed and manufactured with four windows (each $210 \mathrm{~mm}$ long and $40 \mathrm{~mm}$ width); to avoid having escaping gases (e.g. nitrogen through the PCA clearance) from introducing any additional source of error in equilibrium, to ensure that system exposure to ambient room temperature was maximized, and to reduce the initial mass value hence reducing the starting pressure point. The piston and loaded weights were rotated manually during operation, which demonstrated better temperature control compared to thermal input from a motor-driven DWPB.

\subsection{Thermal stability}

The design of the DWPB (including the PCA) provided direct contact for a large volume of material exposed to the ambient temperature, maximizing passive temperature stabilization, reducing the rate of change of PCA temperature, and consequently error terms as a function of thermal expansion. The temperature of the PCA was measured using a dual-channel digital thermometer, with two calibrated k-type thermo-couples The stability of the PCA temperature was shown to be excellent throughout operation, as identified during calibration at the UK National Physical Laboratory (NPL) directly against running from the bottom of the mounting post to points close to the cylinder. the Primary Pressure Standard. The NPL standards room temperature fluctuated randomly 
between $20.02^{\circ} \mathrm{C}$ to $20.49^{\circ} \mathrm{C}$ for a period of 4.5 hours between $11.00 \mathrm{am}$ and $3.30 \mathrm{pm}(11.00$

$201-15.30$ ), with a standard deviation of $0.13^{\circ} \mathrm{C}$. Meanwhile the previously thermally soaked PCA temperature working with this DWPB design, gave readings that changed almost linearly between $20.03^{\circ} \mathrm{C}$ to $20.10^{\circ} \mathrm{C}$ with a standard deviation of $0.02^{\circ} \mathrm{C}$, this being illustrated in Figure 2.

\subsection{Existing Spin-Speed Research}

A significant issue for all DWPB designs is to determine if spin direction and spin speed attribute any systematic error to the pressure balance results. This has received limited reporting in the past, with investigations of the effect of rotation on generated pressures in gas-operated DWPB conducted by Prowse and Hatt [14], and subsequently by Sutton [15]. Both sets of researchers conducted investigations using Type 6-201 gas-operated DWPBs, manufactured by Consolidated Electrodynamics Corp. (CEC, USA), using pistons of

Prowse and Hatt found that at a rotational frequency of approximately $1000 \mathrm{rpm}$ (at 40 $\mathrm{kPa}$ ), the maximum difference in pressure readings with and without a bell-jar in situ was approximately $20 \mathrm{~Pa}$ (when loaded with larger weights). At rotational frequencies of 50 rpm and below (at $70 \mathrm{kPa}$ and above), the pressure determined was independent of a belljar, but decreased as rotational frequency decreased further.

In comparison, Sutton identified that the generated pressure at rotational speeds between $180 \mathrm{rpm}$ to $600 \mathrm{rpm}(3 \mathrm{~Hz}-10 \mathrm{~Hz})$ increased with the square of the rotational frequency, where the calculated pressure was equal to the extrapolated pressure at zero frequency (zero aerodynamic forces). It was suggested that this change was due to the airflow set up 
by the rotating load carrier and weights, potentially forming a spiral flow down thus

226 forming a downward force onto the top of the pressure balance. The results also suggested that this force depended only upon rotational frequency and not load, at rotational speeds between $180 \mathrm{rpm}$ to $480 \mathrm{rpm}$.

229 


\subsection{MEASUREMENTS}

230 Cross-floating (either via flow sensing or pressure sensing) is one of the principle methods 231 to determine the effective area $\left(\mathrm{A}_{0}\right)$ of a PCA under test, where the reference and test 232 DWPBs are interconnected to a common pressure line. Trim weights are added onto either 233 piston until barostatic equilibrium is established, with both pistons rotating and floating at 234 their reference level, simultaneously falling at their natural fall rate. Once an equilibrium 235 condition is established, the effective area under test can be calculated based on the ratio 236 between two masses i.e. on one piston versus the other.

\subsection{Cross-floating and spin/speed experimentation}

An arrangement for a traditional cross-floating experimentation is shown in Figure 3. 240 Effective areas of 2 combinations of the PCAs were determined at $100 \mathrm{kPa}$ using purified nitrogen $\left(99.998 \% \mathrm{~N}_{2}\right)$. A combination of Piston $2\left(\mathrm{P}_{2}\right)$ and Cylinder $3\left(\mathrm{C}_{3}\right)$ was used as a reference (known as $\mathrm{P}_{2} \mathrm{C}_{3}$ ). Test PCAs were combinations of Piston $4\left(\mathrm{P}_{4}\right)$, Cylinder 2 and Cylinder 4, known as $\mathrm{P}_{4} \mathrm{C}_{2}$ and $\mathrm{P}_{4} \mathrm{C}_{4}$ respectively. In order to minimise the error of the total mass loaded on both pistons, the reference DWPB $\left(\mathrm{P}_{2} \mathrm{C}_{3}\right)$ and the test DWPB $\left(\mathrm{P}_{4} \mathrm{C}_{2}\right.$ and $\mathrm{P}_{4} \mathrm{C}_{4}$ ) weight sets were mutually exclusive. High accuracy trim weights (Mettler-Toledo

Investigation of the response of the novel interchangeable PCA units and the DWPB design, has been carried out by changing the speed of rotation between $30 \mathrm{rpm}$ and $90 \mathrm{rpm}$ $(0.5 \mathrm{~Hz}$ and $1.5 \mathrm{~Hz})$, and the direction of rotation either clockwise (cw) or counterclass F1 weight, $1 \mathrm{mg}$ to $100 \mathrm{~g}$ ), were used for balancing purposes. clockwise (ccw) on the reference and/or test DWPBs. This formed 4 different test conditions: i) $\mathrm{cw}-\mathrm{cw}$, ii) $\mathrm{cw}-\mathrm{ccw}$, iii) $\mathrm{ccw}-\mathrm{ccw}$ and iv) $\mathrm{ccw}-\mathrm{cw}$ which was noted as 
being one completed experimental cycle of investigation. Each test PCA combination was experimentally verified over eight cycles, resulting in 32 calculated $\mathrm{A}_{0}$ values per PCA.

\subsection{Determination of equilibrium conditions}

The natural fall rate of the reference DWPB $\left(\mathrm{P}_{2} \mathrm{C}_{3}\right)$ was initially established using a noncontact Eddy Current displacement transducer (eddyNCDT 3300 - Micro-Epsilon Messtechnik $\mathrm{GmbH}$ ) with a linear resolution of $1 \mu \mathrm{m}$. The reference level of the test

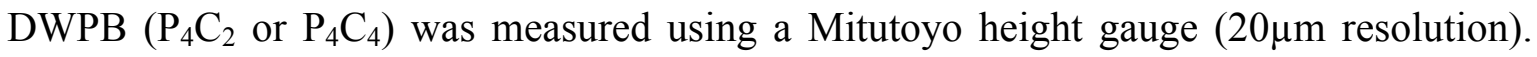
The fall rate value of the reference DWPB was established with $\mathrm{P}_{2} \mathrm{C}_{3}$ in a floating and

The equilibrium conditions were assessed using the differential pressure method, (acting as a null indicator), with a pressure transducer connected across an isolation ball valve (V3). The differential pressure sensor used was a high-accuracy capacitance diaphragm sensor rotating condition at its mid-float position, with ball valve V1 closed.

(MKS Type 698A, 1 Torr range), set to $400 \mathrm{msec}$ response time and $0.01 \mathrm{~Pa}$ resolution, corresponding to $0.1 \mathrm{ppm}$ at $100 \mathrm{kPa}$. The smallest trim weight (sensitivity weight) that produced a detectable pressure change was a $2 \mathrm{mg}$ weight $(0.2 \mathrm{ppm}$ at $100 \mathrm{kPa})$. The A non-contact Compact Instruments CT6/LSR laser tachometer (1 rpm resolution) was used to measure speed of rotation of the piston. A RS 52 Dual Channel K Type digital thermometer (with K-type thermocouples of $0.1^{\circ} \mathrm{C}$ resolution) was used to measure the temperature of both PCAs. 
278 A full uncertainty analysis was completed (with respect to an analysis of the sensitivity 279 coefficients associated with effective area calculation) using the methods described in the 280 ISO Guide to the Expression of Uncertainty in Measurement [16], to provide a traceable 281 statement of uncertainty. The Type A component was based on the standard deviation of 282 the data sets. The Type B components (input parameters with rectangular probability 283 distributions) were estimated based on manufacturers reference data and instrumentation 284 error (weight density, air density, PCA coefficient of thermal expansion, PCA 285 temperature). The Standard Uncertainty of the test effective area at $100 \mathrm{kPa}$ and $20^{\circ} \mathrm{C}$ was 286 calculated as being $8.2 \mathrm{ppm}$, with the Expanded Uncertainty (coverage factor of $\mathrm{k}=2$ ) 287 being $16.4 \mathrm{ppm}$. 


\subsection{RESULTS}

Cross-floating experiments directly against the UK's PG7601 Primary Pressure Standard (with a $35 \mathrm{~mm}$ diameter PCA, NPL Serial No. 602) were completed in order to define traceability of the reference and test PCAs. $\mathrm{P}_{2} \mathrm{C}_{3}$ (reference PCA) was cross-floated at 50 $\mathrm{kPa}, 75 \mathrm{kPa}, 100 \mathrm{kPa}, 200 \mathrm{kPa}, 300 \mathrm{kPa}$ and $400 \mathrm{kPa}$, in falling and rising mode, whilst $\mathrm{P}_{4} \mathrm{C}_{2}$ and $\mathrm{P}_{4} \mathrm{C}_{4}$ were cross-floated at $100 \mathrm{kPa}$ only. The calibrated and traceable effective area values for the three PCAs identified in this work are detailed in Table 2.

Initially, two cross-float experiments were performed sequentially using $\mathrm{P}_{4} \mathrm{C}_{2}$ and $\mathrm{P}_{4} \mathrm{C}_{4}$ respectively, without any mechanical adjustment of the Test DWPB unit (apart from PCA change). Both DWPBs operated with a sensitivity-of-equilibrium of $0.2 \mathrm{ppm}$ as defined by the differential pressure transducer over the entire cross-floating process. The spin times of the reference and test PCAs were approximately 45 and 35 minutes respectively (at $100 \mathrm{kPa}$, and $100 \mathrm{rpm}$ initial speed of rotation) with drop rates of approximately 0.1 $\mathrm{mm} / \mathrm{min}$ further demonstrating geometrical quality of the PCA units.

Single sets of calibrated weights loaded on both DWPBs during cross-floating experiments significantly reduced any systematic error inherited by each weight. Systematic errors incurred by the calibrated class F1 trim weights were deemed to be negligible. The 
313 between DWPBs was typically achieved during a ten minute time frame, with negligible

314 reduction of spin speed of either PCA during this time. The results of the two series of 315 experiments are shown graphically in Figures 4 and 5 respectively, with summary data 316 provided in Table 3. Each figure shows four discrete groupings of data points which are 317 grey scale coded to identify the calculated effective area value.

319 The average values for $\mathrm{P}_{4} \mathrm{C}_{2}$ and $\mathrm{P}_{4} \mathrm{C}_{4}$ were $981.6387 \mathrm{~mm}^{2}$ (sample Standard Deviation (SD) $0.00087 \mathrm{~mm}^{2}$ or $0.87 \mathrm{ppm}$ ) and $981.6293 \mathrm{~mm}^{2}$ (sample SD $0.00075 \mathrm{~mm}^{2}$ or $0.75 \mathrm{ppm}$ ) respectively. There is only minor random variation of effective Area values for each spin condition (as demonstrated by the SD values) for each PCA combination, with no systematic difference or adverse trends between conditions. The random scatter with respect to the $\mathrm{X}$ and $\mathrm{Y}$ axes in both Figures 4 and 5 is a function of manually spinning the DWPBs to the approximate desired rotational speed.

Air temperature, atmospheric pressure and relative humidity were monitored throughout 328 the experimentation showing minor changes of air pressure, allowing buoyancy calculations to be completed and applied. DWPB (Test and Reference) temperatures were also monitored, but found to be stable. 


\section{CONCLUSIONS AND FUTURE WORK}

This research has been initiated with the eventual aim of providing detailed understanding of the influence of PCA surface texture (both random and structured), on the pressure and performance characteristics of gas-operated Dead Weight Pressure Balances at low rotational speeds. The current results have demonstrated confidence in two key elements Firstly, the results have identified that $35 \mathrm{~mm}$ Tungsten Carbide Piston Cylinder Assemblies can be efficiently manufactured to appropriate pressure related tolerances, and of the initial research.

Secondly a simplified, novel, hybrid gas-operated DWPB design has been produced and specifically allow different pistons to be used in common cylinders, with very limited variability of pressure performance. Hence PCA interchangeability has been achieved. This is a significant step forward in the pressure metrology optimisation research. Through careful manufacture, this will allow a large set of pistons to be developed which will be interchangeable, providing a range of piston surfaces that may be modified with respect to surface texture. operated in gauge mode, which exhibits high mechanical, thermal and pressure stability. This provides a stable platform for subsequent interchangeable PCA evaluation at low 
356 With these two elements proven and demonstrated, experimentation concerning the effect 357 of surface texture on pressure performance can be investigated, with confidence that 358 significant variations may be attributed to piston surface form rather than other sources of 359 uncertainty. Clearly, any variations of effective area would need to recognise the 360 relevance of the Standard and Expanded Uncertainty statements. 
1 Heydemann P L M and Welch B E 1975, Piston gages, in Experimental Thermodynamics (Le Neindre B and Vodar B Eds.) Vol II Chap 4 Part 3 Butterworth London

2 Dadson R S, Lewis S L and Peggs G N 1982 The Pressure Balance: Theory and Practice National Physical Laboratory HMSO UK

3 Molinar G 1992 Part II: Pressure measurement in the range from $10^{2} \mathrm{~Pa}$ to $10^{8} \mathrm{~Pa}$ in Modern gas-based temperature and pressure measurements (Timmerhaus K D, Clarck A F and Rizzuto C Eds.) Plenum Press, New York C D 1999 A primary pressure standard at $100 \mathrm{kPa}$ Metrologia, 36 525-529

5 Peggs G N 1997 A method for computing the effective area of a pressure balance from diametral measurement National Physical Laboratory Report MOM 23

6 Neugebauer M 1998 The uncertainty of diameter calibrations with the comparator for diameter and form Measurement Science \& Technology 9 1053-1058 J R, Flack D R, Sabuga W and Jusko O 1999 CCM Key comparison in the pressure range 0.05 $\mathrm{MPa}$ to $1 \mathrm{MPa}$ (gas mediun, gauge mode) - Phase A1: Dimensional measurements and calculation of effective area Metrologia, 36 657-662. 
8 Jain K, Bowers W and Schmidt J W 2003 A primary dead-tester for pressures (0.05 - 1.0) MPa Journal of Research National Institute of Standard and Technology 108 135-145

9 Schmidt J W, Jain K, Miller A P, Bowers W J and Olson D A 2006 Primary pressure standards based on dimensionally characterized piston/cylinder assemblies Metrologia 43 53-59

10 Prowse D B and Hatt D J 1977 The effect of rotation on a gas-operated free-piston pressure gauge Journal of Physics, E: Scientific Instruments 10 450-451

11 Sutton C M 1979 The rotational frequency dependence of a pressure balance Journal of Physics E: Scientific Instruments 12 466-468

12 Wan Mohamed W A M and Petzing J N 2005 Investigating the influence of surface texture on the performance of gas operated Dead Weight Pressure Balances Proceedings of the 4th CMM International Conference on Pressure Metrology from

13 Wan Mohamed W A M 2006 Analysis of surface texture and its affect on pressure 
$411 \quad 14$ Nagano Keiki Co. Ltd. 2008 PD82-89 Pneumatic Dead Weight Tester,

413

15 Ruska Instrument Corporation 2000 Model 2466 - Large Diameter Gas Piston Gauge Document 0105-2466

161993 Guide to the Expression of Uncertainty in Measurement (Geneva: 
420 The authors would like to thank SIRIM Berhad and the Malaysian Ministry of Science, 421 Technology and Innovation, for sponsoring Wan Abd Malik Wan Mohamed during his 422 research studies at Loughborough University. The authors would also like to thank the UK 423 National Physical Laboratory, DH-Budenberg Ltd (UK), Druck Ltd (UK), and Mettler 424 Toledo (Switzerland), for directly supporting the research. 


\begin{tabular}{|c|c|c|c|c|c|c|c|c|c|}
\hline $\begin{array}{c}\text { Dymet } \\
\text { Grade } \\
\text { No. }\end{array}$ & $\begin{array}{c}\text { Average } \\
\text { Grain } \\
\text { Size / } \\
\boldsymbol{\mu m}\end{array}$ & $\begin{array}{c}\text { ISO } \\
\text { Code }\end{array}$ & $\begin{array}{l}\text { Composition by weight (\%) } \\
\mathrm{WC}\end{array}$ & $\begin{array}{c}\text { TaC } \\
\text { Trans. }\end{array}$ & $\mathrm{Cr}_{3} \mathrm{C}_{2}$ & $\mathrm{Co}$ & $\begin{array}{c}\text { Hardness } \\
/ \mathbf{M P a}\end{array}$ & $\begin{array}{c}\text { Density } \\
/ \mathbf{H V 5 0}\end{array}$ & $/ \mathbf{K g m}^{-3}$ \\
\hline $\mathrm{DF} 6$ & 1.0 & $\mathrm{~K} 10$ & 92.7 & 1.0 & 0.3 & 6.0 & 1800 & 1750 & 14900 \\
\hline
\end{tabular}

426

Table 1: Basic composition of Dymet Grade DF6 tungsten

428

carbide and its physical properties

429 


\begin{tabular}{|c|c|c|}
\hline \multirow{2}{*}{$\begin{array}{l}\text { PCA Combination } \\
\text { (PxCy) }\end{array}$} & \multicolumn{2}{|c|}{ Effective Area $\left(A_{0}\right)$} \\
\hline & Value / $\mathbf{m m}^{2}$ & Uncertainty / $(k=2)$ \\
\hline $\mathrm{P}_{2} \mathrm{C}_{3}$ & 981.605 & $0.014(14.3 \mathrm{ppm})$ \\
\hline $\mathrm{P}_{4} \mathrm{C}_{2}$ & 981.635 & 0.014 (14.3 ppm) \\
\hline $\mathrm{P}_{4} \mathrm{C}_{4}$ & 981.625 & 0.014 (14.3 ppm) \\
\hline
\end{tabular}

430 


\begin{tabular}{|l|c|c|}
\hline & $\mathbf{P}_{\mathbf{4}} \mathbf{C}_{\mathbf{2}}$ & $\mathbf{P}_{\mathbf{4}} \mathbf{C}_{\mathbf{4}} \cdot$ \\
\hline Minimum Effective Area $/ \mathbf{m m}^{2}$ & 981.6372 & 981.6273 \\
\hline Maximum Effective Area $/ \mathbf{~ m m}^{2}$ & 981.6399 & 981.6304 \\
\hline Mean Effective Area $/ \mathbf{~ m m}$ & 981.6387 & 981.6293 \\
\hline Standard Deviation / $\mathbf{p p m}$ & 0.75 & 0.87 \\
\hline
\end{tabular}

Table 3: Summary of results of effective area determination for $\mathrm{P}_{4} \mathrm{C}_{2}$ and $\mathrm{P}_{4} \mathrm{C}_{4}$. 


\section{LIST OF FIGURES}

435

436 Figure 1 Schematic diagram (not to scale) of a Dead Weight Pressure Balance

437

438

Figure 2 Schematic diagram of traditional cross-floating system

439

440

Figure 3

Air and instrument temperature profiles with respect to time

441

442

Figure 4

Effective area versus rotational speed/direction for $\mathrm{P} 4 \mathrm{C} 2$ against $\mathrm{P} 2 \mathrm{C} 3$

443

444

Figure 5

Effective area versus rotational speed/direction for P4C4 against $\mathrm{P} 2 \mathrm{C} 3$ 


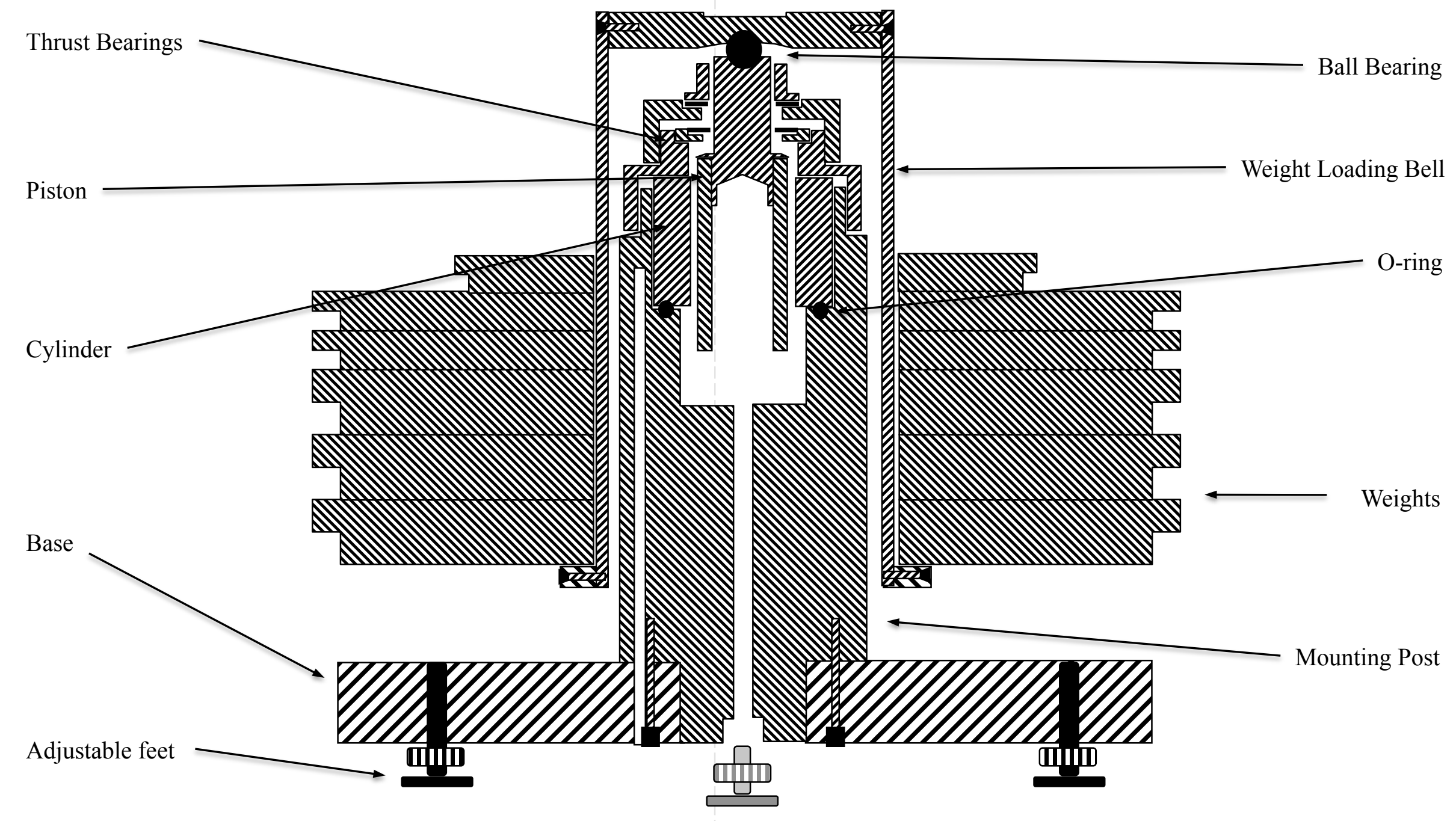




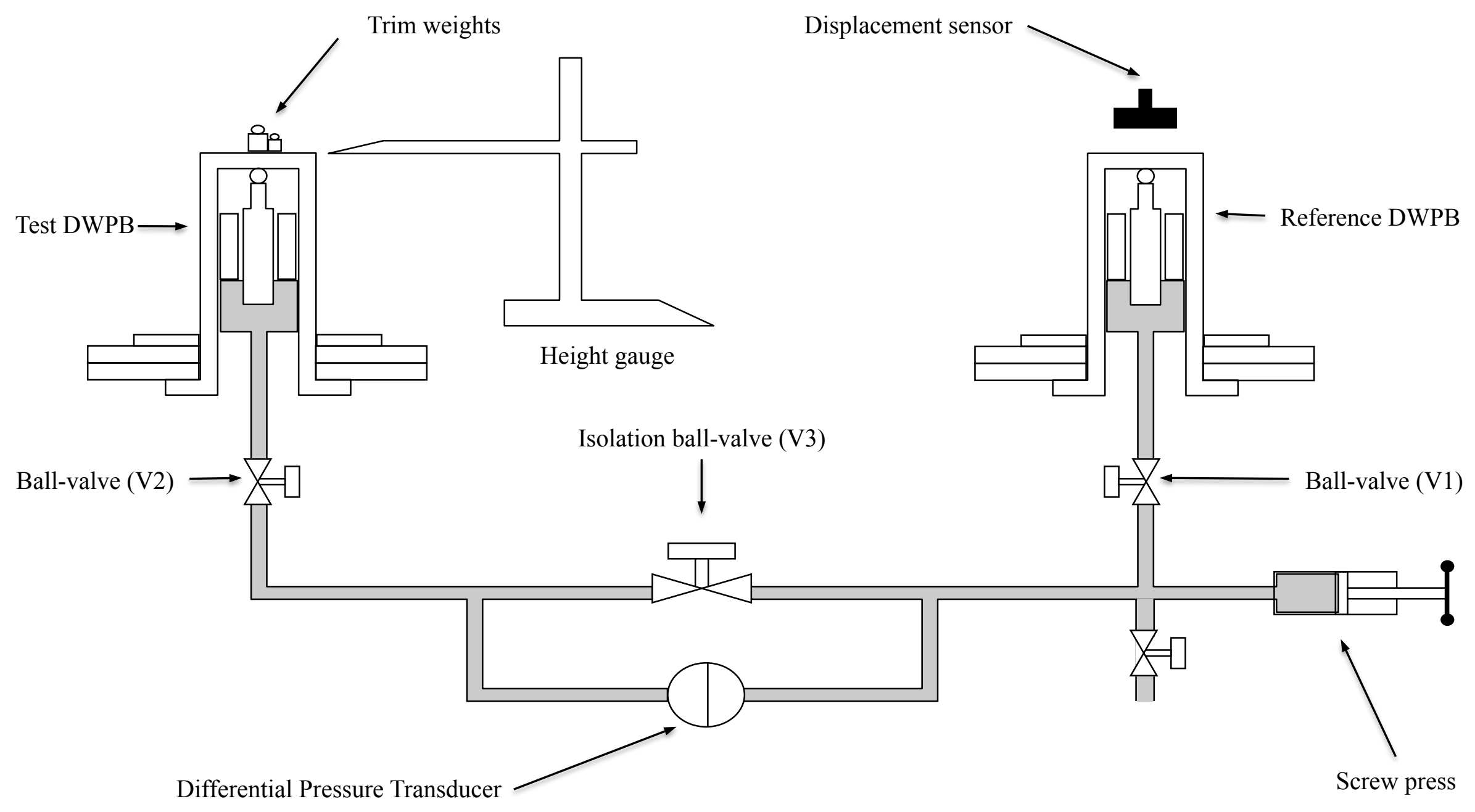




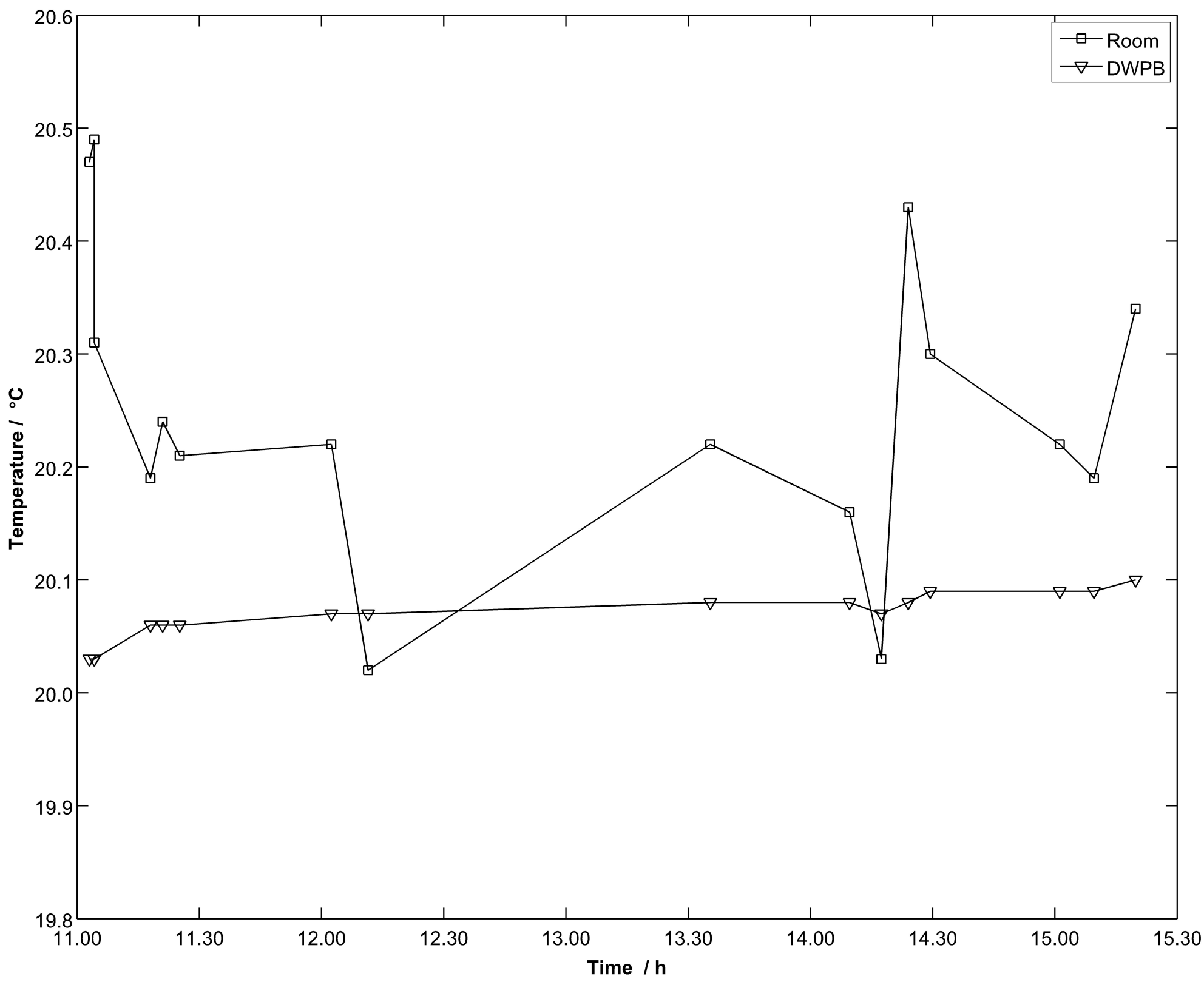




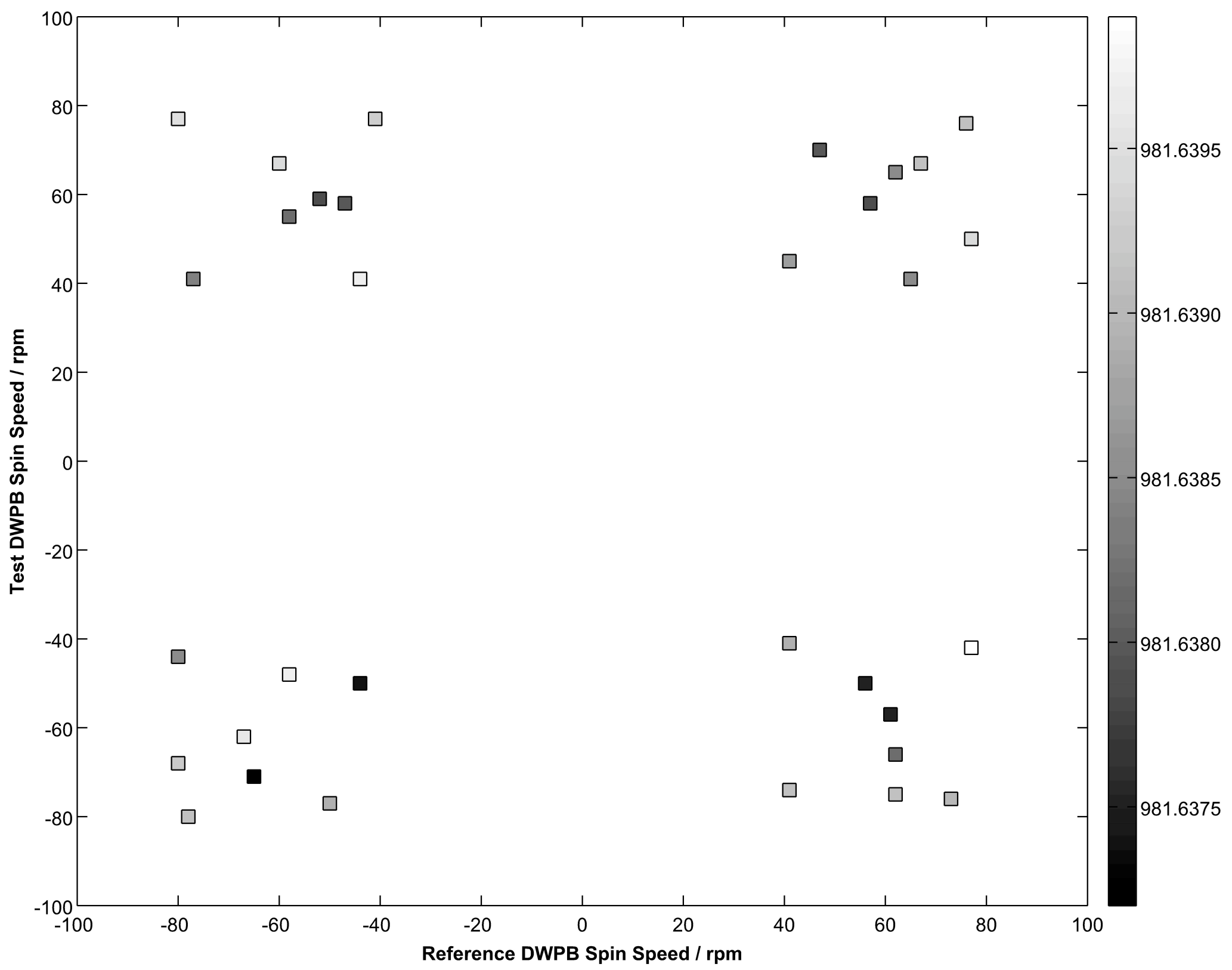




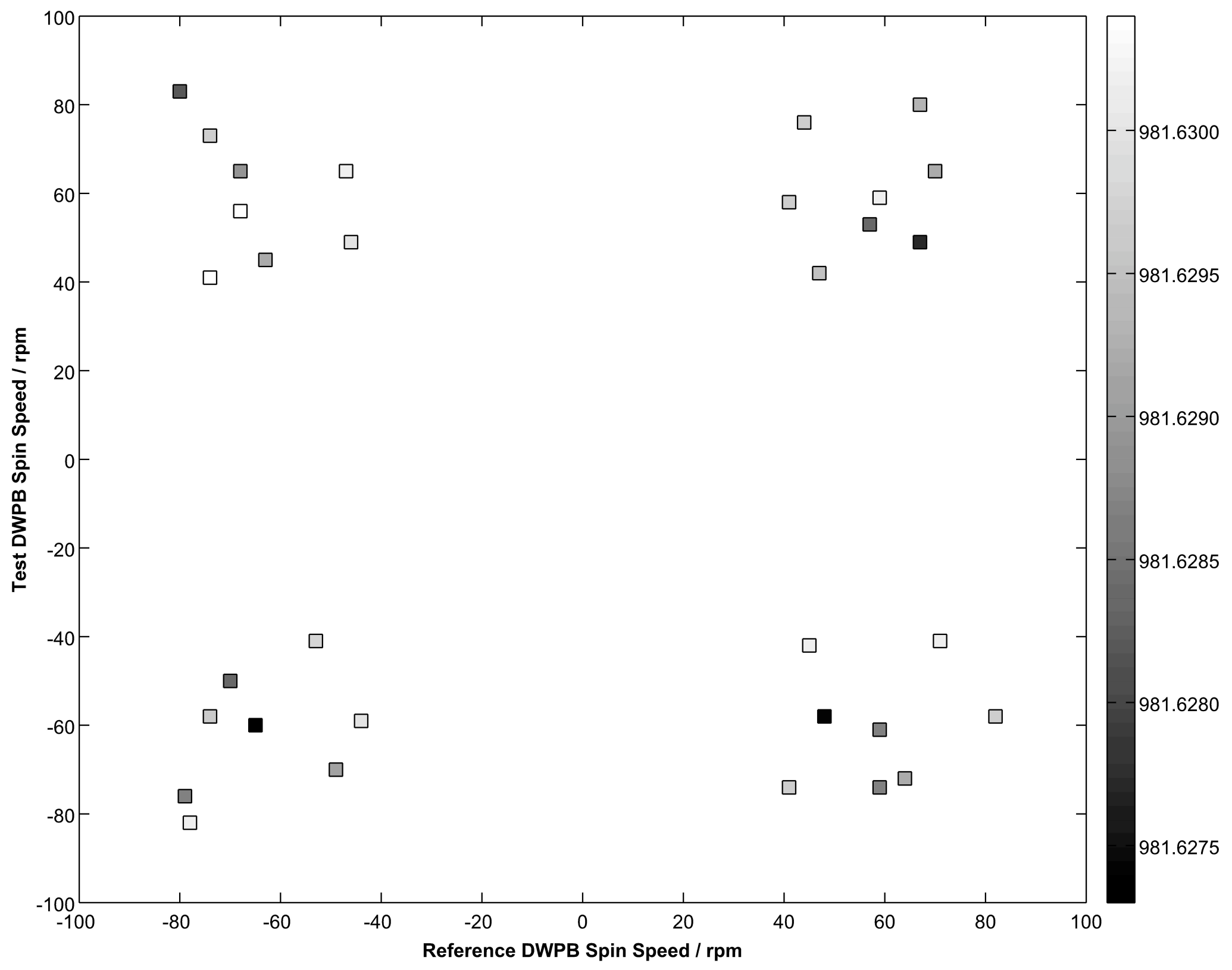

